\title{
On the age vs depth and optical clarity of deep ice at the South Pole
}

\author{
The AMANDA Collaboration ${ }^{*}$
}

\begin{abstract}
The first four strings of phototubes for the AMANDA high-energy neutrino observatory are now frozen in place at a depth of $800-1000 \mathrm{~m}$ in ice at the South Pole. During the 1995-96 season, as many as six more strings will be deployed at greater depths. Provided absorption, scattering and refraction of visible light are sufficiently small, the trajectory of a muon into which a neutrino converts can be determined by using the array of phototubes to measure the arrival times of Cherenkov light emitted by the muon. To help in deciding on the depth for implantation of the six new strings, we discuss models of age vs depth for South Pole ice, we estimate mean free paths for scattering from bubbles and dust as a function of depth and we assess distortion of light paths due to refraction at crystal boundaries and interfaces between air-hydrate inclusions and normal ice. We conclude that the interval $1600-2100 \mathrm{~m}$ will be suitably transparent for a future $1 \mathrm{~km}^{3}$ observatory except possibly in a region a few tens of meters thick at a depth corresponding to a peak in the dust concentration at $60 \mathrm{k}$ year BP.
\end{abstract}

\section{INTRODUCTION}

With the creation of AMANDA (the Antarctic Muon and Neutrino Detector Array), we hope to open a new astronomical window, using neutrinos instead of light (Lowder and others, 1991; Barwick and others, 1992). The goal is to image the trajectories of ultra-high-energy neutrinos created throughout the Universe in very energetic processes such as take place in quasars and other Active Galactic Nuclei. Because the conversion rate of neutrinos into detectable particles is extremely small, the observatory must be huge, eventually of order $1 \mathrm{~km}^{3}$ in volume. All designs share the same idea: a threedimensional array of large phototubes embedded in a transparent medium will look down at the cone of Cherenkov light emitted by an upward-moving muon into which a high-energy neutrino is transformed in passing upward through the Earth. Measurement of arrival times of Cherenkov photons at various phototubes enables the direction of the neutrino to be reconstructed. In contrast to other techniques, which propose to build an observatory in a deep lake or the deep ocean, all of the electronics in the present version of AMANDA sit on the surface of South Pole ice above cables that simply carry signals from the phototubes, and the imaging medium is essentially free of background light such as that due to radioactivity or bioluminescence.

To minimize cost, the strings of phototubes should be

\footnotetext{
* See Appendix. The corresponding author is P. B. Price (Physics Department, University of California, Berkeley, California 94720-7300, U.S.A.).
}

far apart and the spacing of phototubes on each string should be large. To reduce background due to downward-directed muons created in the Earth's atmosphere, the array should be buried deeply and the phototube spacing should be large in order to give a long enough lever arm to determine trajectories very accurately. Our results from the first four strings, which were deployed during the 1993-94 drilling season, showed that Cherenkov light from downward muons propagated diffusively due to scattering from residual air bubbles at the depth interval $800-1000 \mathrm{~m}$ where the phototubes were located (Askebjer and others, 1995). Using a laser to send pulses of light $(510 \mathrm{~nm})$ down optical fibers to various depths, we measured the distribution of arrival times at phototubes at various distances from the emitter. From the excellent fits to a model of random walk with absorption, we were able to determine separately the absorption length (the $e$ folding distance for loss of photons at a particular wavelength) and the scattering length the mean free path between scatterers). The result for the absorption length at $510 \mathrm{~nm}, \lambda_{\text {abs }}=59 \pm 3 \mathrm{~m}$, is larger than that of the clearest ocean water and far larger than the values estimated for laboratory ice and for Lake Baikal. This large value of $\lambda_{\text {abs }}$ will permit us ultimately to construct a neutrino observatory at lower cost than we originally expected. The geometrical scattering length on bubbles, $\lambda_{\text {bub }}$, was found to be $11 \mathrm{~cm}$ at $800 \mathrm{~m}$ and to increase to $26 \mathrm{~cm}$ at $1000 \mathrm{~m}$. In order to take maximum advantage of the information from Cherenkov wave-front arrival times, we plan to implant all future strings of AMANDA phototubes at depths sufficiently great that $\lambda_{\text {bub }}$ is greater than about $20 \mathrm{~m}$.

Figure 1 is a sketch showing the location of the first four AMANDA strings and the proposed location of the 


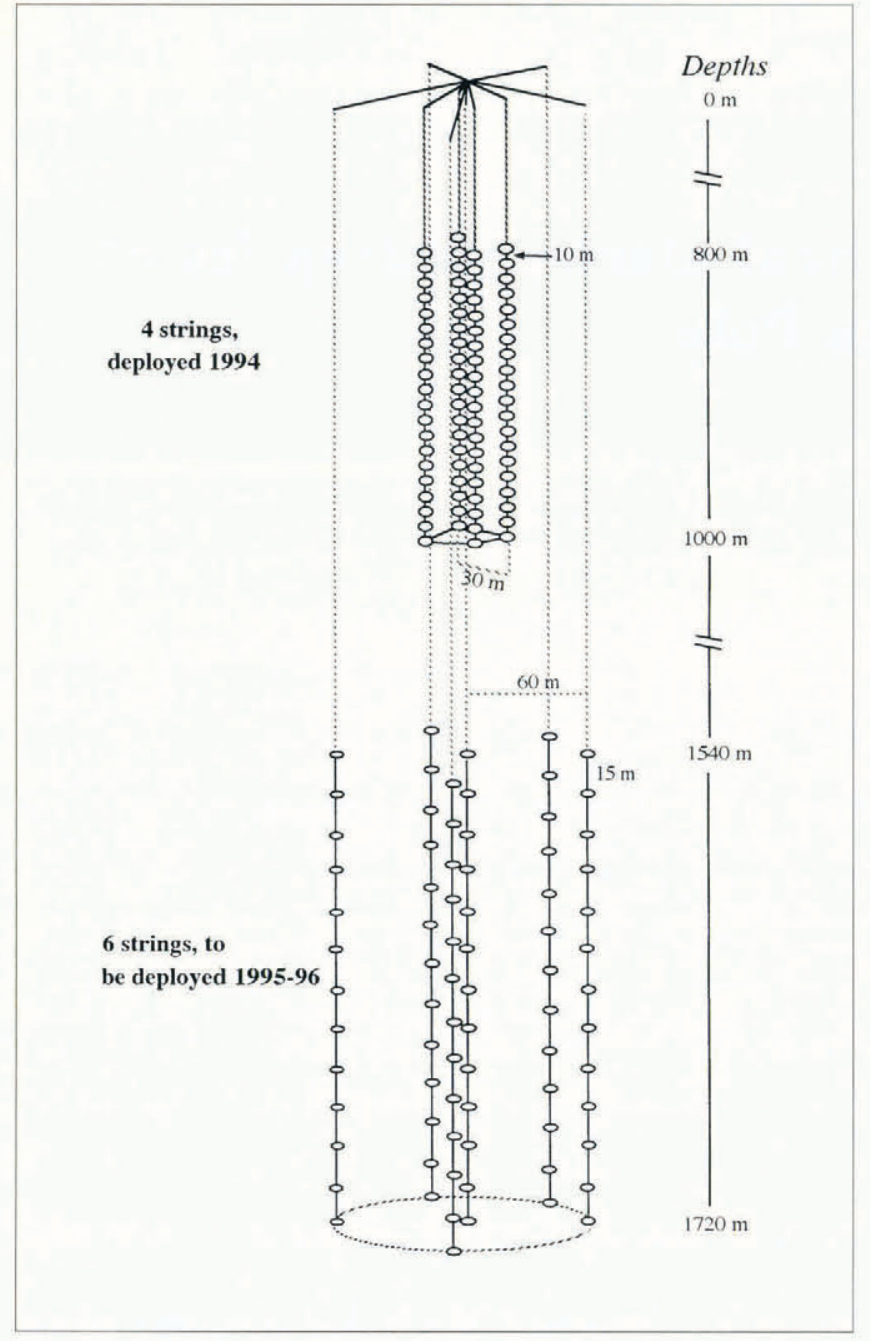

Fig. 1. The AMANDA high-energy neutrino observatory. The top four strings are frozen into the ice at the South Pole and are working. The lower six strings will be deployed at a greater depth to be discussed in this paper.

remaining six strings. In this paper we discuss the factors that must be considered in deciding how deep to implant the remaining six strings. Future plans to proceed to construction of a $1 \mathrm{~km}^{3}$ size neutrino observatory will depend on success in deploying these six strings and on results of measurements with them.

\section{TIME-SCALE MODEL (AGE VS DEPTH)}

To estimate the dust concentration as a function of depth, we require a model of age as a function of depth for South Pole ice. The most important ingredient of such a model is the accumulation rate as a function of time and distance upstream from the site. Since almost no information on accumulation rate upstream from the South Pole has been published, there is little point in developing a sophisticated flowline model. We start with the information in Table 1 on deep cores in ice and on drilling sites. The first four rows are for Greenland sites and the last four are for Antarctic sites. The last row includes information about the South Pole site. No core deeper than $349 \mathrm{~m}$ has been obtained at this site.

Figure 2 displays age vs depth obtained from refer- ences at the bottom of Table 1. Wherever possible, we selected data based on absolute determination of age using stratigraphy (annual layers of high and low $\delta^{18} \mathrm{O}$ values, of electrical conductivity, of dust or of dissolved impurities due, for example, to identifiable volcanic eruptions). In other cases, we followed the authors in associating patterns of $\delta^{18} \mathrm{O},{ }^{10} \mathrm{Be}$ and dust concentrations from core to core with dated events such as the Last Glacial Maximum. To complete the picture, we selectively used ages based on ice-flow models reported by the various authors. In case of any discrepancies from one author to another, we used the most recent work or the one least dependent on flow models. For the Camp Century core, ages estimated from Fourier spectral analyses of $\delta^{18} \mathrm{O}$ profiles and comparisons with features in the deep-sea record differ by a factor $\sim 2$ for times greater than $\sim 10$ kyear. Various reasons have been given for the irregularities in the Camp Century time-scale near the bottom of the core (Dansgaard and others, 1982). We decided to include only the data for depths more than $280 \mathrm{~m}$ above bedrock, for which stratigraphy is said to be accurate to $\pm 3 \%$ (Hammer and others, 1978).

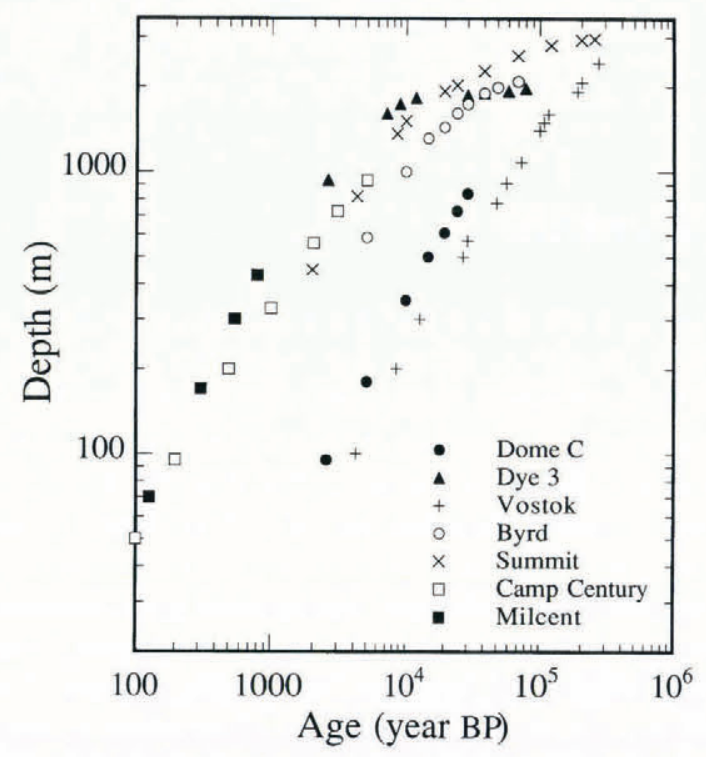

Fig. 2. Depth as a function of age for various deep cores. Curves are meant to guide the eye. Points are a sampling of more extensive data from the references in Table 1.

Figure 3 casts the data in Figure 2 as a universal function in which depth as a function of age is shown in dimensionless coordinates. The dimensionless time is defined as $t^{*} \equiv t a(t) / H$, where $t$ is the time in years, $a$ is the accumulation rate in meters of ice (at density $0.92 \mathrm{Mg} \mathrm{m}^{-3}$ ) per year and $H$ is the ice thickness $(\mathrm{m})$ to bedrock. The dimensionless depth is defined as $d^{*} \equiv d / H$. Following the practice of most authors, for times $t<15$ kyear BP we took $a(t)$ to be its average value during the Holocene, and for $15 \leq t \leq 110$ kyear BP we took $a(t)$ to be a constant fraction of its Holocene value. For Antarctic sites, the fraction is taken to be 0.75 ; for Greenland sites the fraction is taken to be 0.5 . Our adopted values of $a(t)$ are given in columns 7 and 8 of Table 1 . The rationale for assigning a smaller value to 


\begin{tabular}{|c|c|c|c|c|c|c|c|c|c|c|}
\hline Location & $\begin{array}{l}\text { Lateral } \\
\text { flow rate } \\
\text { m year }^{-1}\end{array}$ & $\begin{array}{l}\text { Height, h, } \\
\text { of flow-rate } \\
\text { transition } \\
\mathrm{m}\end{array}$ & $\begin{array}{l}\text { Depth, } H \text {, } \\
\text { to bedrock }\end{array}$ & Elevation & $\begin{array}{c}\text { Surface } \\
\text { temperature }\end{array}$ & $\begin{array}{l}\text { Recenl accum- } \\
\text { ulation rate } \\
\text { m ice year }\end{array}$ & $\begin{array}{c}\text { Accumulation } \\
\text { rate for } \\
15-110 \text { kyear } \\
\text { BP }\end{array}$ & $\begin{array}{c}\text { Bubbles } \\
\text { observed to } \\
\text { disappear at } \\
\mathrm{m}\end{array}$ & $\begin{array}{c}\text { Hydrates } \\
\text { observed to } \\
\text { appear al } \\
\text { m }\end{array}$ & $\begin{array}{l}\text { Depth of } \\
\text { maximum dust } \\
\text { concentration } \\
\mathrm{m}\end{array}$ \\
\hline \multicolumn{11}{|l|}{ Camp } \\
\hline Century & 3.3 & 430 & 1388 & 1890 & -24 & 0.38 & n.s. & $>1388$ & 1100 & 1200 \\
\hline $\begin{array}{l}\text { Milcent } \\
\text { GISP }\end{array}$ & 48 & n.s. & 2340 & 2450 & -22 & 0.53 & n.s. & n.s. & n.s. & n.s. \\
\hline $\begin{array}{l}\text { Dye } 3)^{\circ} \\
\text { GISP }\end{array}$ & 12.3 & 300 & 2037 & 2479 & -19.6 & 0.49 & 0.25 & 1540 & 1092 & n.s. \\
\hline (Summit) ${ }^{d}$ & 0 & 1200 & 3029 & 3238 & -32 & 0.23 & 0.12 & 1350 & n.s. & n.s. \\
\hline Byrd & & & & & & & & & & \\
\hline $\begin{array}{l}\text { Statione } \\
\text { Vostok }\end{array}$ & 12.8 & ? & 2164 & 1520 & -27.9 & 0.13 & 0.1 & 1100 & 727 & 1450 \\
\hline Dome $\mathrm{C}^{\mathrm{g}}$ & 0 & $?$ & 3700 & 3240 & -53.5 & 0.037 & 0.028 & $>800$ & n.s. & 600 \\
\hline South Pole & $8-10^{h}$ & $400-800^{\mathrm{h}}$ & 2900 & 2835 & -51 & $0.073^{i}$ & 0.055 & $\begin{array}{l}>1000 ; \\
\quad \text { predict } \\
\quad \sim 1450\end{array}$ & $\begin{array}{l}\text { predict } \\
\sim 500\end{array}$ & $\begin{array}{l}\text { predict } \\
\sim 1000\end{array}$ \\
\hline
\end{tabular}

a. Dansgaard and Johnsen (1969); Dansgaard and others (1982); Hammer and others (1978).

b. Hammer and others (1978).

c. Dahl-Jensen and Johnsen (1986); Dansgaard and others (1982).

d. Schott and others (1992); Dahl-Jensen (1989); Dansgaard and others (1993).

e. Robin (1983); Lorius and others (1984).

f. Ritz (1989); Lorius and others (1985); Jouzel and others (1993); De Angelis and others (1984).

g. Lorius and others (1979); Petit and others (1981).

h. Koci (personal communication, 1994).

i. Mosley-Thompson and Thompson (1982); Giovinetto (1964); Young and others (1982).

$a(t)$ during the period $15-110$ kyear BP is that large parts of the time-scales given in the references are based on iceflow models for which the authors (with justification) assumed a smaller value of $a(t)$ during that period. This approach should be most successful for sites near ice

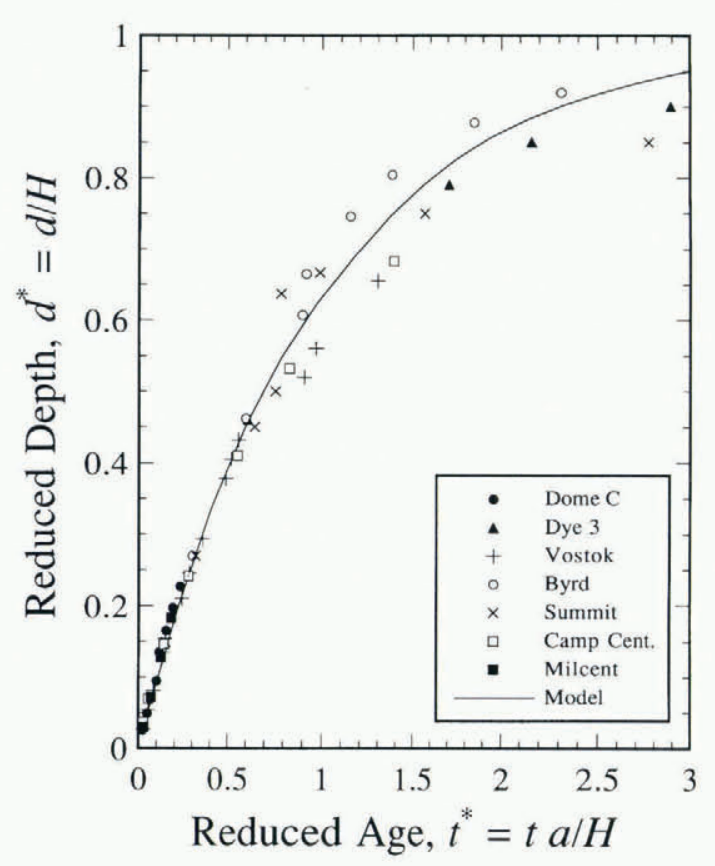

Fig. 3. Universal curve of dimensionless depth os dimensionless age, with $a(t)=$ step function, reduced at 15-100 kyear BP (see text). divides, for which the horizontal flow rate is small. Recently, more sophisticated models have been used, in which the accumulation rate has been taken as continuously varying in a way that can be inferred from the ${ }^{18} \mathrm{O}$ record or the ${ }^{10} \mathrm{Be}$ record less the spikes. Since such data are not available for South Pole ice, we have contented ourselves with the simpler approach using step-function values as described above. For the South Pole site, with its large horizontal flow rate, the accumulation rate far upstream from which the deep ice originated is somewhat smaller than assumed in our simple model (personal communication from E. Mosley-Thompson, 1994). To convey an idea of the uncertainty, we will present three age vs depth curves for the South Pole, one of which (McInnes and Radok, 1984) is based on unrealistically low upstream accumulation rates.

Analytical ice-flow models of age vs depth have evolved from work by Nye (1963), Weertman (1968) and Dansgaard and Johnsen (1969). On the assumption of a constant vertical strain rate with depth, Nye (1963) found the simple dependence of depth on age

$$
d=H(1-\exp (-a t / H))
$$

where $a=$ constant. In the dimensionless version

$$
d^{*}=1-\exp \left(-t^{*}\right) \text {. }
$$

More refined models take into account the variation of horizontal flow rate, vertical strain rate and temperature with depth; the dependence of ice plasticity on temperature and crystal texture; the temperature at the ice- 
bedrock interface; the flow paths of ice from the surface at various times in the past to its present depth, which depends on factors such as the distance of the core from an ice divide; the variation of accumulation rate upstream as a function of time and of the position from which the ice originated; the slope of the bedrock; and the slope at the surface. Little of this information is available for the South Pole site.

The universal curve in Figure 3 is for Equation (2). One sees that for values of reduced depth $d^{*}$ greater than about 0.5 the scatter becomes large. With the universal curve as input, the solid curve in Figure 4 shows our prediction of the age vs depth for the South Pole. The best direct measurements give quite consistent values of accumulation rate for recent times: $a=0.074 \mathrm{~m}$ year $^{-1}$ from annual dust layers extending back to AD 1590 (personal communication from E. Mosley-Thompson, 1994), $a=0.072 \mathrm{~m}$ year $^{-1}$ based on visible stratigraphy in an inclined snow mine for the period $\mathrm{AD} 1950-1770$ (Giovinetto, 1964), and $0.0073 \mathrm{~m}_{\text {year }}^{-1}$ based on a stake network and beta-activity measurements over much of Antarctica (Young and others, 1982). The curve in Figure 4 labeled "AMANDA model" is for $a(t)=0.073 \mathrm{~m}$ year $^{-1}$ back to 15 kyear BP and $0.055 \mathrm{~m}$ year $^{-1}$ before 15 kyear BP.

One attempt to predict age vs depth for ice at the South Pole has been published (McInnes and Radok, 1984). The lower curve in Figure 4 shows their model, which agrees with ours at depths down to $\sim 1300 \mathrm{~m}$, corresponding to an age of $\sim 33$ kyear BP. For greater depths they inferred a much more rapid increase in age with depth than we do, because they assumed an abrupt decrease in accumulation rate from $\sim 0.088$ mear $^{-1}$ at the South Pole to a constant value of $\sim 0.02 \mathrm{~m} \mathrm{year}^{-1}$ for ice more than $\sim 100 \mathrm{~km}$ upstream, which reaches the South Pole at times greater than $\sim 30$ kyear BP. MosleyThompson's recent measurements of accumulation rate at Plateau Remote, near the Pole of Relative Inaccessibility,

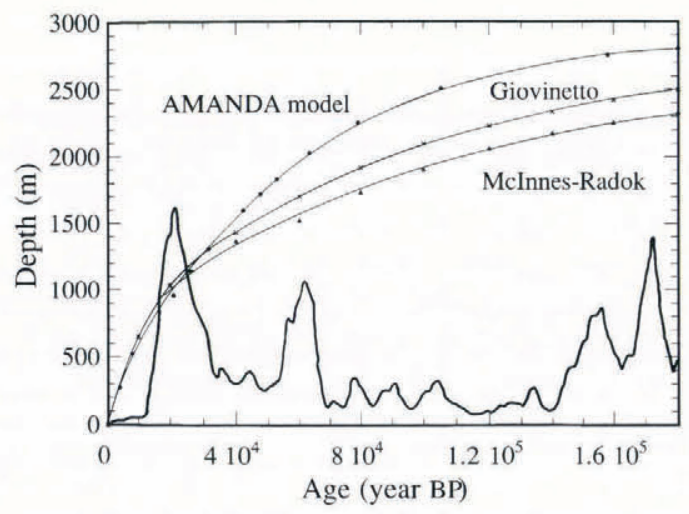

Fig. 4. Models of depth as a function of age for South Pole ice. The AMANDA model is for $a=0.073$ myear $^{-1}$ since 15 kyear BP and $a=0.055$ myear $^{-1}$ before 15 kyear $B P$. Lowest curve is the flowline model of McInnes and Radok (1984). Intermediate curve is based on values of a $(t)$ from Giovinetto. Irregular curve is dust flux at Vostok after smoothing by a cubic spline function (Petit and others, 1990). The scale for dust is linear, with the largest peak corresponding to $7.3 \times 10^{-7}$ cmyear $^{-1}$ (which can be converted into units of $\mathrm{g} \mathrm{cm}^{2}$ year ${ }^{-1}$ by multiplying by density). gave values about twice as large as assumed by McInnes and Radok (1984). Giovinetto (personal communication, $1995)$ has recently estimated upstream values that are about 1.6-2 times as large as those of McInnes and Radok. The middle curve in Figure 4 gives Giovinetto's estimates, which we adopt.

The irregular curve along the abscissa gives the dust flux at the South Pole in arbitrary units as a function of time, inferred from measurements made on an ice core at Vostok Station (see later section for discussion).

\section{DEPTH-DEPENDENGE OF SGATTERING FROM BUBBLES}

A quantity of vital concern to the AMANDA project is the depth-dependence of $\lambda_{\text {bub }}$, the mean free path for scattering of the visible component of Cherenkov radiation off of air bubbles. For smooth spherical bubbles of r.m.s. radius $r$ and number concentration $n, \lambda_{\text {bub }}=$ $\left(n \pi r^{2}\right)^{-1}$. For purposes of discussion, the polar ice can be divided into three depth regimes: at depths shallower than the close-off depth (typically $\sim 60 \mathrm{~m}$ ), the firn is porous to air. At intermediate depths, bubbles exist at an approximately constant number concentration and with mean bubble volume that decreases as hydrostatic pressure increases. At great depths, bubbles transform into a more stable phase consisting of air-hydrate crystals.

Bubbles are formed at the "close-off" depth at which the firn changes into ice. The volume fraction of air trapped in the ice at pore close-off, $V_{\mathrm{c}}$, is given experimentally (Raynaud and Lebel, 1979) by

$V_{\mathrm{c}}\left(\mathrm{cm}^{3} \mathrm{~g}^{-1}\right.$ of ice $)=\left(2 \times 10^{-4}-0.015 / T(\mathrm{~K})\right) P(\mathrm{mbar})$.

$V_{\mathrm{c}}$ depends on atmospheric pressure and thus on altitude at the time of close-off, and depends weakly on temperature. For Vostok Station, $V_{\mathrm{c}}=0.084 \mathrm{~cm}^{3} \mathrm{~g}^{-1}$, whereas for Byrd Station, at an altitude nearly $2000 \mathrm{~m}$ lower than Vostok Station, $V_{c}=0.114 \mathrm{~cm}^{3} \mathrm{~g}^{-1}$. The South Pole, with an altitude intermediate between Vostok and Byrd Stations, would have an intermediate value of $V_{\mathrm{c}}$.

At $z_{\mathrm{c}}$, the ice-equivalent depth for pore close-off, $\rho V_{\mathrm{c}} / n=4 \pi r^{3} / 3$, if all the gas is in bubbles (where $\rho=$ mass density). The number concentration at pore close-off depends on temperature, dust concentration and other climatic factors, but is roughly similar for Vostok and Byrd Stations, the two cores on which detailed studies have been made of bubbles. Since the ice density is roughly constant below the firn layer and the ice temperature does not change much in the first $1000 \mathrm{~m}$, the perfect gas law leads to expressions for the depthdependence of the r.m.s. bubble radius

$$
r=\left(\frac{3 \rho V_{\mathrm{c}} z_{\mathrm{c}}}{4 \pi n z}\right)^{\frac{1}{3}}
$$

and of $1 / \lambda_{\text {bub }}$

$$
1 / \lambda_{\text {bub }}=\left(\frac{3 \rho V_{\mathrm{c}} z_{\mathrm{c}} n^{\frac{1}{2}} \pi^{\frac{1}{2}}}{4 z}\right)^{\frac{2}{3}} .
$$


The latter is shown by the solid curve in Figure 5. The figure also shows data for $1 / \lambda_{\text {bub }}$ at Byrd Station, Vostok Station and the South Pole, derived from measurements by Gow and Williamson (1975) on a Byrd Station core, by Barkov and Lipenkov (1984) on a Vostok Station core and on laser calibration data in situ by the AMANDA collaboration (Askebjer and others, 1995). The two sets of triangular symbols for the AMANDA measurements are put in to remind the reader that the scattering length inferred from the data depends on the angular distribution of scattered light: the lower triangles correspond to the assumption of isotropic scattering from bubbles with rough surfaces (which might come about, for example, if air-hydrate crystals were nucleating at various points on the surfaces) and the upper triangles correspond to the assumption of forward-peaked scattering from smooth spherical bubbles. (The true values should lie somewhere in between.) The curve in Figure 5 is normalized to the data at depths less than $700 \mathrm{~m}$ by choosing $z_{\mathrm{c}}=60 \mathrm{~m}$, a typical depth for pore close-off, and adjusting the bubble concentration at that depth.

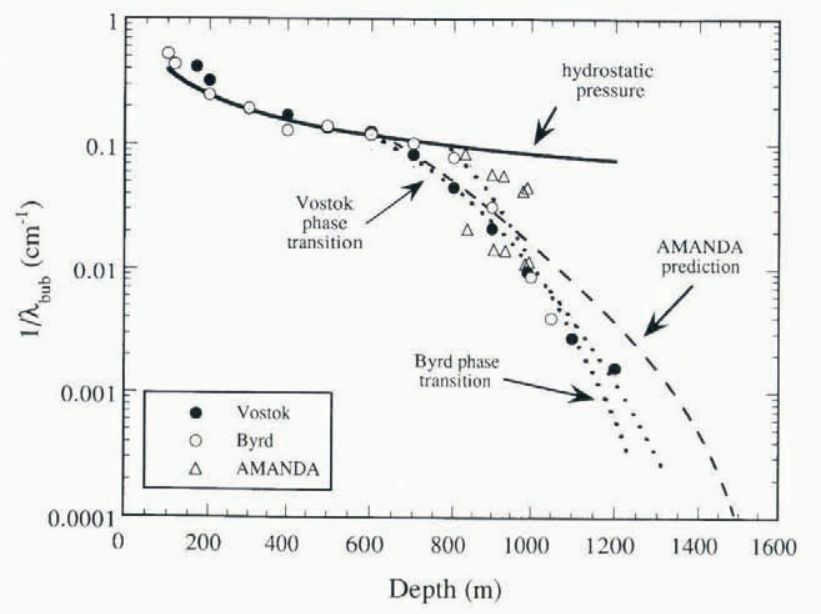

Fig. 5. Inverse scattering length as a function of depth for air bubbles. The data for Byrd Station and Vostok Station were taken from microscopic measurements of bubbles in cores. The AMANDA data for the South Pole were based on light scattering of laser pulses in silu. The solid curve shows the effect of hydrostatic pressure on bubble sizes, assuming all of the air is trapped in bubbles. The dashed curve shows the calculated dependence on depth due to conversion of bubbles into air-hydrate crystals (Price, 1995).

At depths from $100 \mathrm{~m}$ to nearly $700 \mathrm{~m}$, the data for Byrd and Vostok Stations follow the hydrostatic-pressure curve rather well. At greater depths, the inverse scattering length decreases very rapidly with depth, due to a decrease in $n$ brought about by a phase transition. A quantitative diffusion-growth model for the conversion of bubbles into air-hydrate crystals (Price, 1995) both fits the data for $1 / \lambda_{\text {bub }}$ as a function of depth at Vostok and Byrd Stations and predicts the effective disappearance of bubbles at a depth of $\sim 1450 \mathrm{~m}$ in South Pole ice. The dotted curves in Figure 5 show the results of that calculation for Vostok and Byrd Stations and the dashed curve shows the prediction for the South Pole. In the next section, we discuss further the phase transition from the two-phase system (ice + bubbles) into the two-phase system (ice + air hydrate).

\section{GONVERSION OF BUBBLES TO AIR-HYDRATE CRYSTALS}

Miller (1969) first showed that, at sufficiently high pressure, the system (air bubbles + ice) becomes unstable against the transformation into a two-phase system consisting of normal ice + crystals of the cubic clathrate ice structure in which $\mathrm{O}_{2}$ and $\mathrm{N}_{2}$ molecules occupy a fraction of the clathrate cages (experimentally, about $80 \%$ ). In Figure 6, the dashed curves (Miller, 1969) give the dissociation pressures as a function of ice temperature for nitrogen hydrate and "air hydrate". Within the hatched region between the two curves, both bubbles and hydrate crystals should coexist. On the same graph, we show the temperature as a function of depth for some cores for which either measurements or calculations exist. The profile at the South Pole is based on a model with $T$ fixed at $-50^{\circ} \mathrm{C}$ at the surface and at the pressure-melting temperature at bedrock. Seven months after completion of hot-water drilling, temperatures measured at 800 $1000 \mathrm{~m}$ with thermistors imbedded during the AMANDA operation had dropped to within $\sim 0.3^{\circ} \mathrm{C}$ of the model temperatures.

With polarized light, air-hydrate crystals have been observed in a number of core sections. Shoji and Langway (1982, 1987) studied air-hydrate crystals in cores from Dye 3, Camp Century and Byrd Station. Uchida and others (1994a) recently made quantitative measurements of size, shape and concentration of such crystals as a function of depth in Vostok Station cores. In Figure 6 we

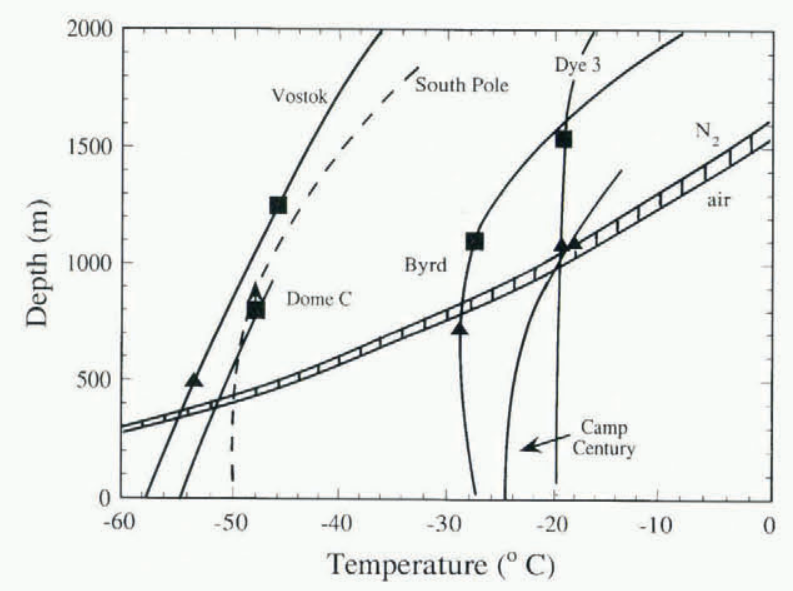

Fig. 6. Temperature profiles for several sites in Greenland and Antarctica, compared with pressure-dissociation equilibria (converted to depths) for nitrogen clathrates and air $\left(\mathrm{N}_{2}+\mathrm{O}_{2}\right)$ hydrates. In the hatched region, both bubbles and hydrate crystals should coexist. The solid triangles indicate depths at which air-hydrate crystals are first observed to appear; the solid squares indicate depths at which air bubbles have completely disappeared. Arrows al solid squares for Dome $C$ and Camp Centry indicate lower limits on depths for disappearance of bubbles. 
have indicated on the depth vs temperature curves the depths at which air-hydrate crystals first appear, as well as the depths at which air bubbles are no longer present. Shoji and Langway (1987) pointed out that the depth at which air-hydrate crystals first appear agrees reasonably well with the depths corresponding to the dissociation pressures calculated for air hydrate by Miller (1969). To explain why air-hydrate crystals are found at depths about $100 \mathrm{~m}$ above the depth corresponding to the equilibrium-phase boundary at Byrd Station (see our Figure 6), Craig and others (1993) pointed out that the hydrate crystals had probably formed at a greater depth just upstream of Byrd Station and had remained metastable following vertical advection of ice through the local phase-boundary depth on the way to their present location at Byrd Station. The advection is attributed to large-scale irregularities in the topography of the bedrock. Since the bedrock topography upstream of the South Pole would not give rise to such upwelling, we predict that air hydrates will appear in increasing concentration at depths exceeding $\sim 500 \mathrm{~m}$ at the South Pole.

Price (1995) showed that the broad transition zone in depth for coexistence of both bubbles and air-hydrate crystals in ice cores was not due to a nucleation barrier but rather to the slowness of diffusion of water molecules through a spherical shell of air-hydrate crystal forming on bubble walls. His model exploited the fact that, whereas the activation energy for diffusion through normal ice is only $0.57 \mathrm{eV}$, the activation energy for diffusion through air hydrate is much higher, $0.9 \mathrm{eV}$ (Uchida and others, $1994 \mathrm{~b})$, which is able to account for the very slow growth rate of air-hydrate crystals.

In Table 1, column 9 gives the depths at which air bubbles in various cores are no longer seen. The same data are displayed in Figure 6. For the South Pole site, we adopt the diffusion model that predicts essentially complete conversion of bubbles into air-hydrate crystals at depths greater than $1450 \mathrm{~m}$.

\section{PARTICLE-SCATTERING GENTERS AS A FUNCTION OF DEPTH}

\section{Insoluble impurities}

In the absence of bubbles, insoluble dust particles with diameters $\sim 0.1-\sim 10 \mu \mathrm{m}$ probably make the most important contribution to scattering of visible light in the ice. The concentration of dust and soluble impurities in the ice has been shown to be directly related to the concentration of atmospheric aerosols. For insoluble particles, the size distribution is log normal, with typical modal diameter ranging from 0.5 (in Dome C; Royer and others, 1983) to $0.6 \mu \mathrm{m}$ (in Vostok Station; De Angelis and others, 1984). The dust concentration in ice cores shows both an annual variation and a long-term anticorrelation with the temperature inferred from $\delta^{18} \mathrm{O}$ measurements. For example, as seen in Table 2, all deep cores show an increase in dust concentration at depths corresponding to the Last Glacial Maximum (LGM) by one order of magnitude for Antarctica and by two orders of magnitude for Greenland. The vertical dust flux
Table 2. Dust concentration in cores at depths for Holocene, LGM and 40 kyear BP (units are particles $\mathrm{ml}$ ${ }^{I}$ with $0.65 \leq$ diam $\leq 0.82 \mu \mathrm{m}$ )

\begin{tabular}{lcccc}
\hline Location & Holocene & LGM & 40 kyear BP & Reference $^{\dagger}$ \\
\hline Camp Century & 2400 & $2 \times 10^{5}$ & Not studied & a \\
Summit & $1 \times 10^{4}$ & Not studied & Not studied & b \\
Byrd Station & 1000 & $1 \times 10^{4}$ & $1500 \mathrm{ml}^{-1}$ & $\mathrm{a}$ \\
Dome C & 4200 & $7 \times 10^{4}$ & $1.1 \times 10^{4 *}$ & $\mathrm{c}$ \\
Vostok Station & 5650 & $6.5 \times 10^{4}$ & $1.6 \times 10^{4}$ & $\mathrm{~d}$ \\
South Pole Station & 1450 & Predict & Predict & $\mathrm{e}$ \\
& & $1.9 \times 10^{4}$ & 3350 & \\
\hline
\end{tabular}

* Measurement made near bottom of core, at $~ 30$ kyear BP.

a. Thompson (1977); b. Palais and others (1992); c. Petit and others (1981); d. De Angelis and others (1984); Petit and others (1990); e. Gayley and Ram (1985); Mosley-Thompson (personal communication, 1994).

increases as global temperature decreases, both because of increased continental aridity and because of higher wind velocity. (The flux is roughly proportional to the desert area of nearby continents and to the cube of wind velocity.) For a given annual dust flux, the concentration deposited in ice is inversely proportional to snowaccumulation rate and is roughly constant for the entire Antarctic continent (Petit and others, 1990).

In Figure 4, the irregular curve shows the dust flux as a function of time at Vostok Station inferred from measurements on an ice core (Petit and others, 1990). By comparing this curve with the models of age vs depth on the same graph, we obtain estimates of the depths at the South Pole at which maxima and minima in the dust concentration occur. (To convert from flux to concentration, divide by accumulation rate.) For example, each of the models predicts that the largest peak, corresponding to the Last Glacial Maximum, will be found at a depth of $\sim 1000 \mathrm{~m}$. The next maximum, at $\sim 60$ kyear $B P$, is predicted to occur at $\sim 1700 \mathrm{~m}$ with the Giovinetto model.

Taking together the requirements that all bubbles must have converted into air-hydrate crystals (which dictates that the detectors be deeper than $1450 \mathrm{~m}$ ), that depths with high dust concentration be avoided and that depths of large horizontal shear $(>2100 \mathrm{~m})$ be avoided, the Giovinetto model leads to the following constraints:

Strings instrumented over a vertical distance of $200 \mathrm{~m}$ could be deployed in the depth interval $\sim 1400$ to $1600 \mathrm{~m}$ between the 18 and 60 kyear dust peaks, or

strings instrumented over a vertical distance of $300 \mathrm{~m}$ could be deployed in the depth interval $\sim 1800$ to $\sim 2100 \mathrm{~m}$ between the 60 and 160 kyear dust peaks.

We must, however, allow for an uncertainty of at least $100-200 \mathrm{~m}$ in the location of the 60 kyear dust peak. When we drill the holes for the six deeper AMANDA strings, we intend to use the pulsed laser technique to measure the scattering mean free path $\lambda_{\text {scat }}$ as a function of depth throughout the region of interest from 1450 to $2100 \mathrm{~m}$. In order to optimize the vertical location of the phototubes on the six strings, we must determine the 
depth of the 60 kyear BP dust peak while drilling the first hole. As the AMANDA observatory expands beyond the set of ten strings envisaged in Figure 1, additional strings will be implanted so as to avoid the dust peak.

We next estimate the mean free path for light scattering from dust at the South Pole for the maximum and minimum values of the dust concentration. We use data collected in Table 2, which gives our estimates of the dust concentrations in various cores at depths corresponding to three times: the Holocene (from the present back to $\sim 13$ kyear BP), for which the dust concentration has been roughly constant and quite low; the Last Glacial Maximum, at $\sim 18$ kyear BP; and a time $\sim 40$ kyear BP, typical of the region of minimal dust concentration. Data at the South Pole exist only for a depth of 100-349 m (personal communication from E. Mosley-Thompson, 1994). To predict the concentration at 40 kyear BP at the South Pole, we note that the ratio of the concentration at 40 kyear BP and during the Holocene is $\sim 1.5$ for Byrd Station, 2.6 for Dome C and 2.9 for Vostok Station. We assume that the average of these three values, a factor 2.3, holds at the South Pole. Noting that the ratio of concentrations at the LGM and during the Holocene is 10, 17 and 12 for Byrd Station, Dome C and Vostok Station, respectively, we adopt a factor $\sim 13$ for the South Pole. Our predictions appear in row 6 of Table 2.

We estimate the mean free path for light scattering from dust in two ways. The more direct approach uses the data in Table 3 on the diameter distribution of dust measured in an ice core in the depth interval $100349 \mathrm{~m}$ at the South Pole. No deeper core has yet been obtained.) Column 2 gives the numbers of particles per $\mathrm{ml}$ and column 3 gives the total cross-sectional area per $\mathrm{ml}$ assuming $\pi r^{2}$ per particle. Summing the entries gives $7 \times 10^{4}$ particles with diameter $>0.1 \mu \mathrm{m}$ and total crosssectional area $\mathrm{ml}^{-1}$ of $7 \times 10^{-5} \mathrm{~cm}^{1}$. (For a log-normal size distribution peaked at $0.5 \mu \mathrm{m}$, the area $\mathrm{ml}^{-1}$ below $0.1 \mu \mathrm{m}$ (Gayley and Ram, 1985) is negligible and the area $\mathrm{ml}^{-1}$ above $2 \mu \mathrm{m}$ (personal communication from E. Mosley-Thompson, 1994) is as given in Table 3.) The reciprocal of the latter quantity is $\lambda_{\text {scat }}$, which is seen to be $\sim 140 \mathrm{~m}$. Assuming that the relative concentrations in the

Table 3. Size distribution of dust in a South Pole core al depth of $100349 \mathrm{~m}$

$\underset{\mu \mathrm{m}}{\text { Diameter }} \quad$ No. $\mathrm{ml}^{l^{*}} \quad$ Area $\mathrm{ml}^{1}$

$\begin{array}{ccc}0.1-0.4 & 6 \times 10^{4} & 1.7 \times 10^{-5} \mathrm{~cm}^{-1} \\ 0.4-0.8 & 8200 & 2 \times 10^{-5} \\ 0.81-1.0 & 885 & 6 \times 10^{-6} \\ 1.01-1.25 & 578 & 6 \times 10^{-6} \\ 1.26-1.59 & 343 & 5.5 \times 10^{-6} \\ 1.6-2.0 & 190 & 5 \times 10^{-6} \\ >2.0 & 235 & 1.2 \times 10^{-5} \\ \geq 0.1 & 7 \times 10^{4} & 7 \times 10^{-5}\end{array}$

* Gayley and Ram (1985); Mosley-Thompson (personal communication, 1994). different diameter intervals do not change with depth, we can scale the mean free path to different times, leading to the prediction that $\lambda_{\text {scat }} \approx 11 \mathrm{~m}$ at the Last Glacial Maximum and $\lambda_{\text {scat }} \approx 60 \mathrm{~m}$ at a depth corresponding to 40 kyear BP.

The second approach is based on the study of light scattering and absorption by dust suspended in a Dome C core. Royer and others (1983) used a gonionephelometer to measure the intensity of light at $546 \mathrm{~nm}$ scattered at angles from $15^{\circ}$ to $150^{\circ}$ in freshly melted ice. Using Mie theory to fit the angular distribution of scattered light, they derived average values of the scattering coefficient $b=3.46 \pm 0.2 \times 10^{-2} \mathrm{~m}^{-1}$ for Holocene samples, $b=$ $10 \pm 2.5 \times 10^{-2} \mathrm{~m}^{-1}$ for LGM samples and $\sim 5 \times 10^{-2}$ $\mathrm{m}^{-1}$ for samples near the bottom of the core (corresponding to $\sim 30$ kyear BP). From these results, we infer a mean free path $\lambda_{\text {scat }}=20 \mathrm{~m}$ for dust near the bottom of the core at Dome C. Scaling with accumulation rate, we infer $\lambda_{\text {scat }}=40 \mathrm{~m}$ for dust at $1500 \mathrm{~m}$ at the South Pole. Comparison of this result with that obtained by the first approach provides an indication of the uncertainty in the value of $\lambda_{\text {scat }}$.

\section{Soluble impurities}

Studies of the paleochemistry of deep Antarctic cores have shown that the mass in soluble impurities was comparable to or even greater than the mass in insoluble impurities (Royer and others, 1983; De Angelis and others, 1984; Legrand and others, 1988). Since the soluble impurities might have remained intact until chemistry was done on melted core samples, we discuss to what extent they would contribute to light scattering in deep ice. The concentration of soluble impurities in recent ice at Vostok Station (Legrand and others, 1988) is about twice as great as in recent ice taken from a $130 \mathrm{~m}$ South Pole core (Kirchner and Delmas, 1988). We use this factor 2 to scale concentrations of various soluble impurities from Vostok Station to the South Pole at 40 kyear BP. We group soluble impurities in two classes - those that remain liquid at a temperature $\sim 45^{\circ}$ to $-50^{\circ} \mathrm{C}$ pertinent to South Pole ice (comprising sulfuric, nitric and hydrochloric acid) and those (mainly $\mathrm{NaCl}$ ) that are solid at those temperatures.

The acids are transported to the South Pole mainly as hydrated sub-micron droplets. During compaction and grain growth, ice-crystal boundaries sweep up ions such as $\mathrm{SO}_{4}{ }^{2-}$, leading to a concentration of acids in threecrystal boundaries called veins (Wolff and others, 1988). As a worst-case estimate of $\lambda_{\text {scat }}$, we assume that all acid $\left(\sim 100 \mathrm{ng} \mathrm{g}^{-1}\right)$ reaches veins. For a crystal size of $\sim 4 \mathrm{~mm}$, the same as measured in the Vostok Station core at a depth of $1500 \mathrm{~m}$ (Lipenkov and others, 1989), the vein diameter would be $2 \mu \mathrm{m}$, the refractive index due to the acid would be $\sim 1.37$ (sulfuric acid, at $3.7 \mathrm{Ml}^{-1}$ ) and $\lambda_{\text {scat }} \approx 10 \mathrm{~m}$. For a more optimistic estimate, assume that the acid is uniformly spread out in two-crystal boundaries. Then, the thickness of the acid layer would be only $\sim 0.1 \mathrm{~nm}$ and light would be unaffected by its presence.

The salts, sprayed into the atmosphere during sea storms, diffuse as aerosols, a small fraction reaching the South Pole. $20 \%$ of snowflakes and ice particles collected from the air by filters near South Pole Station have $\mathrm{NaCl}$ 
at their centers (Kumai, 1976). We estimate that the concentration of salt grains is $\sim 50 \mathrm{ng} \mathrm{g}^{-1}$ at $1500 \mathrm{~m}$ depth in South Pole ice. To make a worst-case estimate, we assume that no salt particles dissolve in surrounding water or ice either in the atmosphere, in snow near the surface or in deep ice. We also assume that during grain growth, crystal boundaries will pass through the salt grains, leaving them unaltered. The contribution to $\lambda_{\text {scat }}$ depends on the size distribution of salt grains, which is poorly known for aerosols and unknown for deep ice. We estimate that $\lambda_{\text {scat }}(\mathrm{m}) \approx 26 r_{\text {r.m.s. }}(\mu \mathrm{m})$. If $r_{\text {r.m.s. }}=$ $0.4 \mu \mathrm{m}$, the scattering mean free path becomes $\sim 10 \mathrm{~m}$. We think it very unlikely, however, that salt grains will survive intact for 40 kyear. It is much more likely that sub-micron salt grains will react or dissolve as crystal boundaries pass through them. Wolff and others (1988) estimated that $\sim 10 \%$ or more of the sulfuric acid could be in crystal boundaries. Then, $\mathrm{NaCl}$ would react at boundaries to form $\mathrm{Na}_{2} \mathrm{SO}_{4}+\mathrm{HCl}$. The solubility of $\mathrm{Na}_{2} \mathrm{SO}_{4}$ in water is $\sim 40 \mathrm{~g} 100 \mathrm{ml}^{-1}$, so that some or all of the salt would end up dissolved in liquid films at crystal boundaries. Even partial dissolution would facilitate diffusion of $\mathrm{Na}^{+}$and $\mathrm{Cl}$ ions through the lattice. Either of the two effects would increase $\lambda_{\text {scat }}$.

\section{REFRACTION BY AIR-HYDRATE CRYSTALS}

In the last section, we concluded that in the depth interval $1600-1850 \mathrm{~m}$ at the South Pole all bubbles will have transformed into air-hydrate crystals and $\lambda_{\text {scat }}$ will be of order $40-60 \mathrm{~m}$, independent of the age vs depth model. Because the air-hydrate crystals have dimensions very large relative to the wavelength of light, Cherenkov light will undergo refraction rather than scattering at interfaces between air-hydrate and hexagonal ice crystals. The quantitative effect of the hydrate crystals on light transmission will depend on their size, shape, concentration and refractive index relative to that of the normal ice in which they are imbedded. Using X-ray diffraction, Hondoh and others (1990) verified the cubic clathrate nature of natural air-hydrate crystals in a Dye 3 deep core. From the Raman intensities of the stretching modes of $\mathrm{N}_{2}$ and $\mathrm{O}_{2}$, Nakahara and others (1988) inferred a composition ratio of $\mathrm{N}_{2}: \mathrm{O}_{2}$ to be $1.6-1.9$ in the clathrate structure of these same hydrate crystals. Shoji and Langway (1982, 1987) made optical studies and did laboratory experiments on air-hydrate crystals in ice cores from Dye 3, Camp Century and Byrd Station. Uchida (personal communication, 1994) determined that the ratio of the refractive index of natural air hydrate in icecore samples relative to the refractive index of hexagonal ice is 1.004 . Uchida and others (1994a) recently made an extensive study of the depth profiles of the shape, volume concentration, number concentration and mean volume per crystal of air-hydrate crystals in Vostok Station icecore samples. They found a typical concentration of airhydrate crystals of $\sim 500 \mathrm{~cm}^{-3}$, a typical diameter of $\sim 100 \mu \mathrm{m}$ and a predominance of spherical shapes, from which we infer a typical mean path of $\sim 15 \mathrm{~cm}$ for encounter of a light ray with such crystals. To reach a phototube at a distance of, say, $25 \mathrm{~m}$ requires $\sim 170$ traversals of such crystals. Integrating over impact parameters gives an r.m.s. refraction angle $\delta_{\text {rms }}=1^{\circ}$ for one encouter. Although the distribution of single refractions is strongly non-Gaussian, after $\sim 170$ refractions the distribution is very closely Gaussian, with $\sigma_{\delta}=\delta_{\text {rms }}\left(L / \lambda_{\text {refr }}\right)^{1 / 2} \approx 13^{\circ}$. The distribution of transverse displacements is also nearly Gaussian, with $\sigma_{\mathrm{d}}=$ $\delta_{\text {rms }}\left(L / \lambda_{\text {refr }}\right)^{3 / 2} \lambda_{\text {refr }} e^{-1 / 2} \approx 3.3 \mathrm{~m}$.

We calculated the timing dispersion due to photons that are emitted from all points along a muon's trajectory and that refract into a photomultiplied tube. Absorption prevents the integral from diverging. The distribution of arrival times has a sharp peak due to photons emitted from the part of the muon track near the Cherenkov angle and a weak but very broad component due to photons coming from the muon track far upstream. For a muon passing close to one of the PMTs, we find that the angular error is $\Delta \alpha \approx\left(\tan \theta_{\mathrm{C}}\right) /\left(\tan ^{2} \theta_{\mathrm{C}}+1\right) \Delta t n / c L_{0}$, where $L_{0}$ is the distance along the Cherenkov angle to the muon track. For $\lambda_{\text {abs }}=300 \mathrm{~m}$, which is the case for light at a wavelength of $\sim 400 \mathrm{~nm}$, we find that even for a long distance like $L_{0}=50 \mathrm{~m}$, the fraction of photons refracted more than $1^{\circ}$ is only $\sim 6 \%$, and the associated time delay is $8 \mathrm{~ns}$. The conclusion is that air-hydrate crystals cause far less serious problems for AMANDA than does scattering by dust. From the Fresnel equations for reflection, we conclude that the fractional reduction in intensity of transmitted light after $10^{2}$ encounters is only $\sim 10^{3}$. Thus, because of the nearly perfect match of refractive index to that of hexagonal ice, air-hydrate crystals have virtually no effect on the imaging of muon trajectories.

\section{REFRACTION AT ICE-CRYSTAL BOUNDARIES}

With its hexagonal crystal structure, ice has a refractive index along the $c$ axis that is larger than that in the basal plane by a factor of 1.001. Again, assuming a mean crystal size of $4 \mathrm{~mm}$, a light ray in South Pole ice would refract $\sim 6000$ times in traversing a distance of $25 \mathrm{~m}$. As a simple estimate, we assume a random distribution of $c$ axes with a typical angle of $45^{\circ}$ between $c$ axes in adjacent crystals. We estimate an r.m.s. deflection angle $\sigma_{\delta}=0.1^{\circ}$, a net deflection of $12^{\circ}$, a transverse displacement $\sigma_{\delta} \approx 5 \mathrm{~m}$ and a fractional loss of intensity of transmitted light $\sim$ few $10^{-3}$. In a more detailed analysis, to be published elsewhere, we conclude that large-angle scattering from dust causes greater degradation of trajectory information than does a series of small-angle refractions at ice-crystal boundaries and air-hydrate crystal boundaries.

\section{CONCLUSIONS}

1. The AMANDA age vs depth model in Figure 4 probably underestimates ages at great depths because the choice of $a(t)=0.055 \mathrm{~m}^{-1}$ dear $^{-1}$ during the interval 15 110 kyear BP is higher than recent values estimated by Mosley-Thompson (personal communication, 1994) and Giovinetto (personal communication, 1995). The flowline model of McInnes Radok overestimates the ages at depths greater than $\sim 1300 \mathrm{~m}$, because of the very small (and incorrect) value $a(t)=0.02 \mathrm{~m}$ year $^{-1}$ at distances 
more than $\sim 180 \mathrm{~km}$ upstream. We adopt a model based on estimates of $a(t)$ by Giovinetto and shown in Figure 4.

2. A diffusion growth model that fits Vostok and Byrd Stations core data predicts that the transformation of bubbles into air-hydrate crystals at the South Pole will be complete at depths below $\sim 1450 \mathrm{~m}$.

3. Using data on the size distribution of dust in a shallow South Pole core (100-349 m), together with systematics of depth profiles of dust concentrations at other sites, we estimate a mean free path of $\sim 40-60 \mathrm{~m}$ for scattering of light from dust in the depth intervals $1400-1600 \mathrm{~m}$ and $1800-2100 \mathrm{~m}$ at which AMANDA detectors might be deployed. At a depth of $\sim 1700 \mathrm{~m}$ corresponding to the peak in the dust concentration at $\sim 60$ kyear BP, the scattering mean free path is estimated to drop to $\sim 13$ $20 \mathrm{~m}$. Such a short mean free path is confined to a vertical layer a few tens of meters thick.

4. The main water-soluble impurities are liquid acids and salt grains. For an acid concentration of $100 \mathrm{ng} \mathrm{g}^{-1}$, the fraction of the acid $(f \approx 0.4-0.9)$ that segregates to $\mu \mathrm{m}$ sized veins at three-crystal boundaries is estimated to scatter light with $\lambda_{\text {scat }} \approx 10 \mathrm{~m} \mathrm{f}^{-1}$, the exact value depending on crystal size and shape. The $\sim 50 \mathrm{ng} \mathrm{g}^{-1}$ of salt grains will interact with moving crystal boundaries, where they will at least partially dissolve in concentrated acid films in the boundaries. The contribution to $\lambda_{\text {scat }}$ will depend on the r.m.s. radius (in $\mu \mathrm{m}$ ) of surviving grains and on the fraction of survivors as $\lambda_{\text {scat }}(\mathrm{m}) \approx 26 r_{\text {r.m.s. }} / f$. To determine more quantitatively the contributions of soluble impurities to scattering must await measurements to be made with the six future strings.

5. Taking into account the age vs depth relationship, the depth profile of the dust concentration for the deep Vostok Station core, the expected depth for bubble disappearance $(1450 \mathrm{~m})$ and the depth $(\sim 2500 \mathrm{~m})$ at which the horizontal ice-flow rate is thought to change rapidly with depth (personal communication from $\mathrm{B}$. Koci, 1994), we conclude that

the safest depth interval in which to deploy AMANDA phototubes is between 1800 and $2100 \mathrm{~m}$. If drilling capabilities limit us to shallower depths, the interval $1400-1600 \mathrm{~m}$ is our second choice. The pulsed-laser technique can be used to locate the 60 kyear BP peak in dust concentration and to optimize the choice of depth interval for a second-generation version of AMANDA.

6. Due to the small difference in refractive index between air-hydrate and normal hexagonal ice crystals, refraction at the interfaces between the two types of crystal will have a small effect on the trajectories of Cherenkov light rays emitted by muons in the ice and loss of light due to reflections at the boundaries will be negligibly small.

7. Similar reasoning leads to the conclusion that, due to the small difference in refractive index parallel to and perpendicular to the $c$ axis in normal hexagonal ice, refraction at the interfaces between randomly distributed ice crystals will have a small effect on the trajectories of Cherenkov light rays emitted by muons and loss of light due to reflections at the boundaries will be negligibly small.

\section{ACKNOWLEDGEMENTS}

We are indebted to B. Koci and the entire PICO organization for their excellent support with the ice drilling. This work was supported in part by the U.S. National Science Foundation, the K.A. Wallenberg Foundation, the Swedish Natural Science Research Council, the G. Gustafsson Foundation, Swedish Polar Research and the Graduate School of the University of Wisconsin, Madison. We thank R. B. Alley, S. P. Davis, P. Duval, J. Fitzpatrick, A.J. Gow, T. Hondoh, B. Koci, V. Ya. Lipenkov, S. L. Miller, E. Mosley-Thompson, R. G. Pain, J. M. Palais, J.R. Petit, M. Ram, C. F. Raymond and T. Uchida for helpful discussion.

\section{REFERENCES}

Askebjer, P. and 29 others. 1995. Optical properties of the South Pole ice at depths between 0.8 and 1 kilometer. Science, 267 5201), 1147 1150 .

Barkov, N. I. and V. Ya. Lipenkov. 1984. Kolichestvennaya kharakteristika struktury l'da do glubiny $1400 \mathrm{~m}$ v rayone stantsii Vostok v Antarktide [Numerical characteristics of ice structure down to a depth of $1400 \mathrm{~m}$ in the region of Vostok station, Antarctica]. Mater. Glyatsiol. Issled. 51, 178186.

Barwick, S. and 6 others. 1992. Neutrino astronomy on the $1 \mathrm{~km}^{2}$ scale. J. Phys. G. Nucl. Plyss, 18, 225247.

Craig, H., H. Shoji and C. C. Langway, Jr. 1993. Nonequilibrium air clathrate hydrates in Antarcic ice: a paleopiezometer for polar ice caps. Proc. Nall. Acad. Sci. U.S.A., 90 23), 11,416-11,418.

Dahl-Jensen, D. 1989. Two-dimensional thermo-mechanical modelling of flow and depth age profiles near the ice divide in central Greenland. Amn. Glaciol., 12, 31-36.

Dahl-Jensen, D. and S.J. Johnsen. 1986. Palaeotemperatures still exist in the Greenland ice sheet. Nature, 206059$), 250-252$.

Dansgaard, W. and S.J. Johnsen. 1969. A flow model and a time scale for the ice core from Camp Century, Greenland. J. Glaciol., 8 53 , 215223.

Dansgaard, W. and six others. 1982. A new Greenland deep ice core. Science, 2184579$), 1273-1277$

Dansgaard, W. and 10 others. 1993. Evidence for general instability of past climate from a 250-kyr ice-core record. Nature, 364 6434), $218-220$.

De Angelis, M., M. Legrand, J.R. Petit, N. I. Barkov, Ye.S. Korotkevich and V.M. Kotlyakov. 1984. Soluble and insoluble impurities along the $950 \mathrm{~m}$ deep Vostok ice core Antarctica)climatic implications. J. Atmos. Chem., 1, 215-239.

Gayley, R. 1. and M. Ram. 1985. Atmospheric dust in polar ice and the background aerosol. J. Geophys, Res., 90 D7), 12,921-12,925.

Giovinetto, M. B. 1964. The drainage system of Antarctica: accumulation. Antarct. Res, Ser., 2, 127-155.

Gow, A.J. and T. Williamson. 1975. Gas inclusions in the Antarctic ice sheet and their glaciological significance. J. Geophys. Res., 80 (36), $5101-5108$

Hammer, C. U., H. B. Clausen, W. Dansgaard, N. Gundestrup, S.J. Johnsen and N. Reeh. 1978. Dating of Greenland ice cores by flow models, isotopes, volcanic debris, and continental dust. 7. Glaciol., $2082), 3-26$

Hondoh, T., H. Anzai, A. Goto, S. Mae, A. Higashi and C. C. Langway, Jr. 1990. The crystallographic structure of the natural air-hydrate in Greenland Dye-3 decp ice core. Journal of Inclusion Phenomena and Molecular Recognilion in Chemistry, 812 , 17-24.

Jouzel, J. and 16 others. 1993. Extending the Vostok ice-core record of palacoclimate to the penultimate glacial period. Nature, 3646436$)$, $407-412$.

Kirchner, S. and R.J. Delmas. 1988. A 1000 year glaciochemical study at the South Pole. Amm. Glaciol., 10, $80-84$.

Kumai, M. 1976. Identification of nuclei and concentrations of chemical species in snow crystals sampled at the South Pole. J. Almos. Sci., 33 (15), $833-841$.

Legrand, M. R., C. Lorius, N. I. Barkov and V. N. Petrov. 1988. Vostok (Antarctica) ice core: atmospheric chemistry changes over the last climatic cycle (160,000 years). Atmos. Environ., 22 2), 317-331.

Lipenkov, V.Ya., N.I. Barkov, P. Duval and P. Pimienta. 1989. 
Crystalline texture of the $2083 \mathrm{~m}$ ice core at Vostok station, Antarctica. J. Glaciol., 35 (121), $392-398$.

Lorius, C., L. Mertivat, J. Jouzel and M. Pourchet. 1979. A 30,000-yr isotope climatic record from Antarctic ice. Nature, 280 5724$), 644$ 648 .

Lorius. C., D. Raynaud, J. -R. Petit, J. Jouzel and L. Merlivat. 1984. Late-glacial maximum-Holocene atmospheric and ice-thickness changes from Antarctic ice-core studies. Amn. Glaciol., 5, 8894.

Lorius, C. and 6 others. 1985. A 150,000-year climatic record from Antarctic ice. Nature, 316 6029), 591-596.

Lowder, D. and 6 others. 1991. Observation of muons using the polar ice cap as a Cerenkov detector. Nature, 353 6342), 331-333.

McInnes, B. and U. Radok. 1984. Estimated ages and temperatures of South Pole ice. Antarct. J. U.S., 19 (1), 10-12.

Miller, S. L. 1969. Clathrate hydrates of air in Antarctic ice. Science, $\mathbf{1 6 5}(3892), 489-490$

Mosley-Thompson, E. and L.G. Thompson. 1982. Nine centuries of microparticle deposition at the South Pole. Quat. Res., 17 (1), 1-13.

Nakahara, J., Y. Shigesato, A. Higashi, T. Hondoh and C. C. Langway, Jr. 1988. Raman spectra of natural clathrates in deep ice cores. Philos. Mag. B, $\mathbf{5 7}$ (3), 421-430.

Nye, J.F. 1963. Correction factor for accumulation measured by the thickness of the annual layers in an ice sheet. J. Glaciol., 4 (36), 785 788.

Palais, J. M., M.S. Germani and G.A. Zielinski. 1992. Inter-hemispheric transport of volcanic ash from a 1259 A.D. volcanic eruption to the Greenland and Antarctic ice sheets. Geophys. Res. Lell., 19 (8), $801-804$.

Petit, J. -R., M. Briat and A. Royer. 1981. Ice age aerosol content from East Antarctic ice core samples and past wind strength. Nature, 293 (5831), 391-394.

Petit, J. R., L. Mounier, J. Jouzel, Ye. S. Korotkevich, V. I. Kotlyakov and C. Lorius. 1990. Palacoclimatological and chronological implications of the Vostok core dust record. Nature, $\mathbf{3 4 3} 6253), 56-58$.

Price, P. B. 1995. Kinetics of conversion of air bubbles to air hydrate crystals in Antarctic ice. Science, 267, $1802-1804$.

Raynaud, D. and B. Lebel. 1979. Total gas content and surface elevation of polar ice sheets. Nature. 281 (5729), 289-291.

Ritz, C. 1989. Interpretation of the temperature profile measured at Vostok, East Antarctica. Ann. Glaciol., 12, 138-144.

Robin, G.de Q. 1983. Presentation of data. In Robin, G.de Q., ed. Climate record in polar ice sheets. Cambridge, etc., Cambridge University Press, 94-122.

Royer, A., M. De Angelis and J. R. Petit. 1983. A 30000 year record of physical and optical properties of microparticles from an East Antarctic ice core and implications for paleoclimate reconstruction models. Climalic Change, 5 4 , $381-412$.

Schøtt, C., E. D. Waddington and C. F. Raymond. 1992. Predicted time-scales for GISP2 and GRIP boreholes at Summit, Greenland. J. Glaciol., 38 (128), 162-168.

Shoji, H. and C. C. Langway, Jr. 1982. Air hydrate inclusions in fresh ice core. Nature, 298 (5874), 548-550.

Shoji, H. and C. C. Langway, Jr. 1987. Microscopic observations of the air hydrate-bubble. Transformation process in glacier ice. 7 . Phys (Paris), 48, Colloq. C1, 551-556. (Supplément au 3.

Thompson, L. G. 1977. Variations in microparticle concentration, size distribution and elemental composition found in Camp Century, Greenland, and Byrd station, Antarctica, deep ice cores. International Association of Hydrological Sciences Publication 118 (Symposium at Grenoble 1975 - Isotopes and Impurities in Snow and Ice), 351-364.

Uchida, T., T. Hondoh, S. Mae, V. Ya. Lipenkov and P. Duval. 1994a. Air-hydrate crystals in deep ice-core samples from Vostok Station, Antarctica. J. Glaciol., 40(134), 79-86.

Uchida, T., T. Hondoh, S. Mae, P. Duval and V. Ya. Lipenkov. 1994b. Effects of temperature and pressure on the transformation rate from air bubbles to air-hydrate crystals in ice sheets. Ann. Glaciol., 20, 143 147.

Weertman, J. 1968. Comparison between measured and theoretical temperature profiles of the Camp Century, Greenland, borehole. $f$. Geophys. Res., 73(8), 2691-2700.

Wolff, E.W., R. Mulvaney and K. Oates. 1988. The location of impurities in Antarctic ice. Ann. Glaciol., 11, 194-197.

Young, N. W., M. Pourchet, V. M. Kotlyakov, P. A. Korolev and M. B. Dyugerov. 1982. Accumulation distribution in the IAGP area, Antarctica: $90^{\circ} \mathrm{E}-150^{\circ}$ E. Ann. Glaciol., 3, 333-338.

\section{APPENDIX}

\section{THE AMANDA COLLABORATION}

Members of the AMANDA Collaboration are: P. Askebjer Physics Department, Stockholm University, Stockholm S-106 91, Sweden), S. Barwick (Physics Department, University of California, Irvine, California 92717, U.S.A.), L. Bergström and A. Bouchta Physics Department, Stockholm University, Stockholm S-106 91, Sweden), S. Carius (Physics Department, Uppsala University, Uppsala S-752 20, Sweden), A. Coulthard and K. Engel Physics Department, University of Wisconsin-Madison, Madison, Wisconsin 53706 , U.S.A.), B. Erlandsson and A. Goobar (Physics Department, Stockholm University, Stockholm S-106 91, Sweden), L. Gray (Physics Department, University of Wisconsin-Madison, Madison, Wisconsin 53706 , U.S.A.), A. Hallgren (Physics Department, Uppsala University, Uppsala S-752 20, Sweden), F. Halzen (Physics Department, University of Wisconsin-Madison, Madison, Wisconsin 53706, U.S.A.), P. O. Hulth (Physics Department, Stockholm University, Stockholm S-106 91, Sweden), J. Jacobsen (Physics Department, University of Wisconsin-Madison, Madison, Wisconsin 53706 , U.S.A.), S. Johansson (Physics Department, Stockholm University, Stockholm S-106 91, Sweden; currently at Physics Department, Jönköping University, Jönköping, Sweden), V. Kandhadai and I. Liubarsky (Physics Department, University of Wisconsin-Madison, Madison, Wisconsin 53706, U.S.A.), D. Lowder and T. Miller (Physics Department, University of California, Berkeley, California 94720-7300, U.S.A.; currently at Bartol Research Institute, Newark, Delaware 19716, U.S.A.), P. Mock (Physics Department, University of California, Irvine, California 92717, U.S.A.), R. Morse (Physics Department, University of Wisconsin-Madison, Madison, Wisconsin 53706, U.S.A.), R. Porrata (Physics Department, University of California, Irvine, California 92717, U.S.A.), P.B. Price and A. Richards (Physics Department, University of California, Berkeley, California 94720-7300, U.S.A.), H. Rubenstein (Physics Department, Uppsala University, Uppsala S-752 20, Sweden), J.C. Spang (Physics Department, University of Wisconsin-Madison, Madison, Wisconsin 53706, U.S.A.), Q. Sun (Physics Department, Stockholm University, Stockholm S-106 91, Sweden), S. Tilav (Physics Department, University of Wisconsin-Madison, Madison, Wisconsin 53706, U.S.A.), C. Walck (Physics Department, Stockholm University, Stockholm S-106 91, Sweden) and G. Yodh Physics Department, University of California, Irvine, California 92717, U.S.A.) 